\title{
Wideband Printed Antenna Design Using a Shape Blending Algorithm
}

\author{
Aiting Wu, Zhonghai Zhang, and Boran Guan \\ College of Electronics and Information, Hangzhou Dianzi University, No. 1158, 2nd Street, Xiasha District, Hangzhou 310018, China \\ Correspondence should be addressed to Aiting Wu; wuaiting@hdu.edu.cn
}

Received 7 January 2017; Revised 26 February 2017; Accepted 9 March 2017; Published 23 March 2017

Academic Editor: Jaume Anguera

Copyright (C) 2017 Aiting Wu et al. This is an open access article distributed under the Creative Commons Attribution License, which permits unrestricted use, distribution, and reproduction in any medium, provided the original work is properly cited.

\begin{abstract}
The shape of the tuning stub of the wide slot printed antenna is an important factor which affects the antenna's performances. In this paper, a new design and optimization method of wideband printed slot antenna using a shape blending algorithm is presented. The proposed antenna consists of a wide rectangular slot and a tuning stub, whose profile is formed by the shape blending outcome from a pie and a diamond shape. The method is used to design an ultra-wideband antenna. The impact on the impedance bandwidth through the antenna geometry change with the different shape blending results has been investigated and analyzed. To verify the proposed design, the antenna prototype was designed, fabricated, and measured. The measured results are compared with the simulation and show good agreement.
\end{abstract}

\section{Introduction}

It has always been the goal of antenna engineers to improve antenna performance such as impedance bandwidth, size, and gain. Antenna researchers and engineers have developed different kinds of tools to facilitate the design process and effectively design antennas that meet the given specifications. The conventional design methods usually begin with an existing geometry found in the literature or inspired by the prior knowledge. Then various geometry parameter investigations are conducted to improve or optimize certain antenna characteristics. Generally, the whole design process significantly depends on the engineer's expertise and knowledge and it takes time.

Optimization techniques are then proposed to either synthesize an antenna from given radiation characteristics or simply improve existing antenna designs. Brute-force search routines that utilize numerical methods to provide radiation properties of antennas generally consume a considerable amount of time. Therefore, a great deal of work has been devoted to achieving design and optimization process which could find an optimum solution effectively and accurately [1]. Evolutionary algorithms, such as genetic algorithms (GA) and particle swarm optimization (PSO), are extensively reported to optimize various electromagnetic devices [2-6]. Typical applications of the algorithms make use of objective function, which treat the design process as a nonlinear problem and make it like a black-box. However, low efficiency and poor performance are the common problems of these types of algorithms [7].

Coplanar waveguide- (CPW-) fed wide slot antennas have been widely used in communication systems due to their several beneficial merits such as mechanical durability, conformability, compactness, and cheap manufacturing costs. Before long, people found that the different designs of wide slot and tuning stub of the printed antenna have an effective impact on the impedance bandwidth [8-17]. However, generally, it will take antenna designers a lot of time and efforts to find the proper geometry of the wide slots and tuning stubs to meet the specification. Evolutionary algorithms are also proposed to apply on the design process $[18,19]$. Inefficiency remains the biggest challenge. For example, the design process in [18] took about 21 days.

Based on our previous research work in [20], in this paper, a novel technique for antenna design and optimization process, shape blending algorithm, is presented and further applied in the design of a CPW-fed wide slot antenna. The tuning stub's shape of the proposed antenna is constructed 


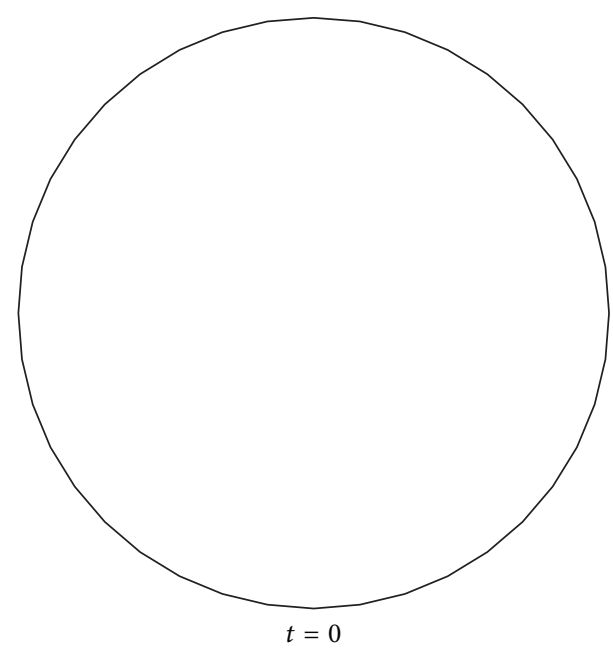

(a)

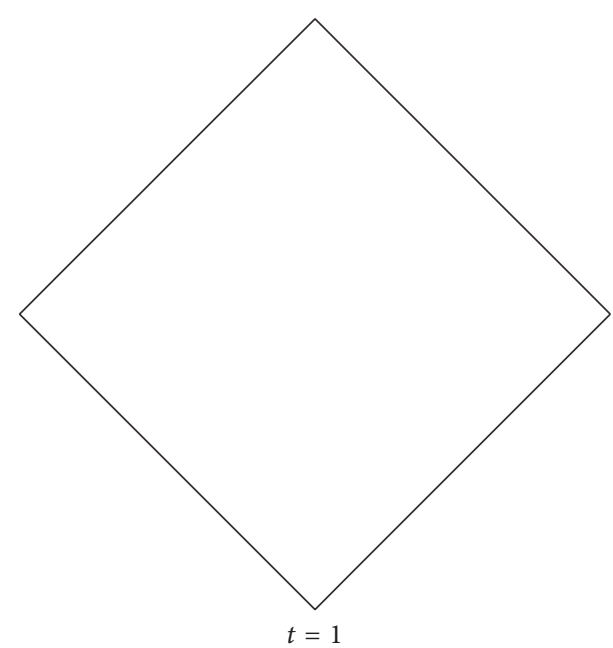

(b)

FIgURE 1: Source shape and destination shape. (a) Source. (b) Destination.

by the shape blending result between a pie and a diamond. Formulating the curve edge of the tuning stub by shape blending, the impedance bandwidth of the antenna can be improved significantly if the parameters of the shape blending process are selected appropriately. The proposed design algorithm has a good performance, with the automated design process less than 70 seconds through simulation. The main novelty of our contribution is that a brand new design and optimization method, shape blending, is introduced and used in the antenna design. Compared with the traditional optimization methods, such as evolutionary algorithms, it has much better performance.

\section{Shape Blending Algorithm}

Shape blending, also known as shape morphing or shape averaging, is pioneered in computer science and is an important technique in computer graphics. It continuously transforms a source shape to a destination shape. Although computer scientists are supposed to take most of the credit for the development of the technique, other domains such as industrial design and entertainment have successfully put the shape blending algorithm into practice [21, 22].

This paper firstly demonstrates how the shape blending algorithm is used to construct the curve edge of the tuning stub of the slot antenna and improve the antenna impedance bandwidth gradually. In the first step, a pie and a diamond are selected as the source shape and destination shape, respectively, as shown in Figure 1.

The following step is to figure out the corresponding relationship between the vertices in the source shape and destination shape, which is called vertex correspondence. There are different kinds of methods to find the correspondence relationships. The selected approach is generally determined by the geometric properties presented in the source and destination shapes and the practical application context. The ray firing approach is one of the most fundamental

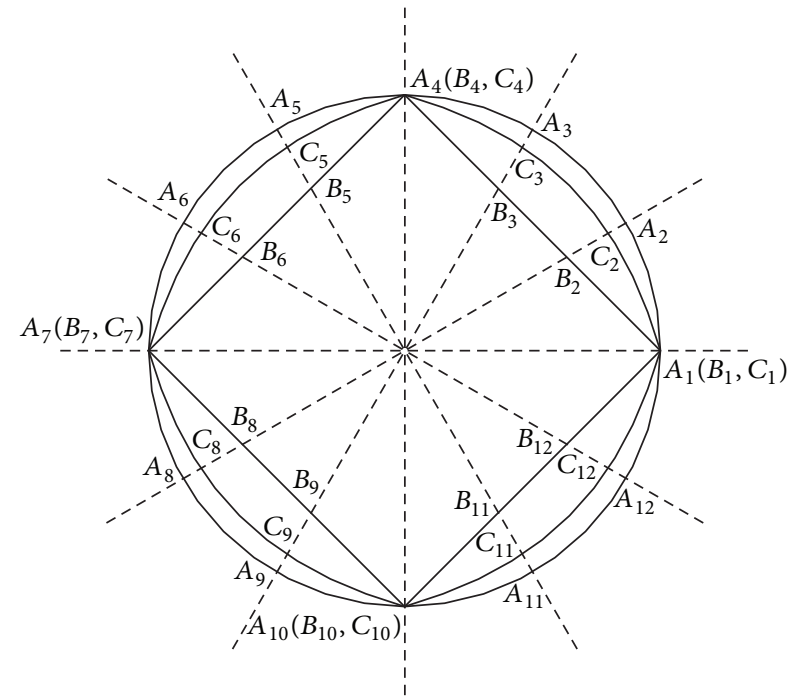

FIgURE 2: Ray firing method to find the vertex correspondence between a pie and a diamond.

methods and it is adopted here, where several rays are fired from the center of the source shape. Each half-line will have one intersecting point with the source shape and destination shape, respectively. Then the two intersecting points are regarded to be corresponding. Figure 2 illustrates the principle. The vertices $A_{1}-A_{12}$ of the pie shape correspond to the vertices $B_{1}-B_{12}$ of the diamond.

Then the next problem is to determine the moving path between each pair of the corresponding vertices, that is, how a vertex $A_{n}$ moves to its corresponding vertex $B_{n}$. This is called the vertex path problem. The simple linear interpolation is used here. As shown in Figure 2, a series of vertices $C_{n}$ could be obtained by linearly interpolating on each pair of the vertices $A_{n}$ and $B_{n}$. Then the polygon $C$ formed by connecting 

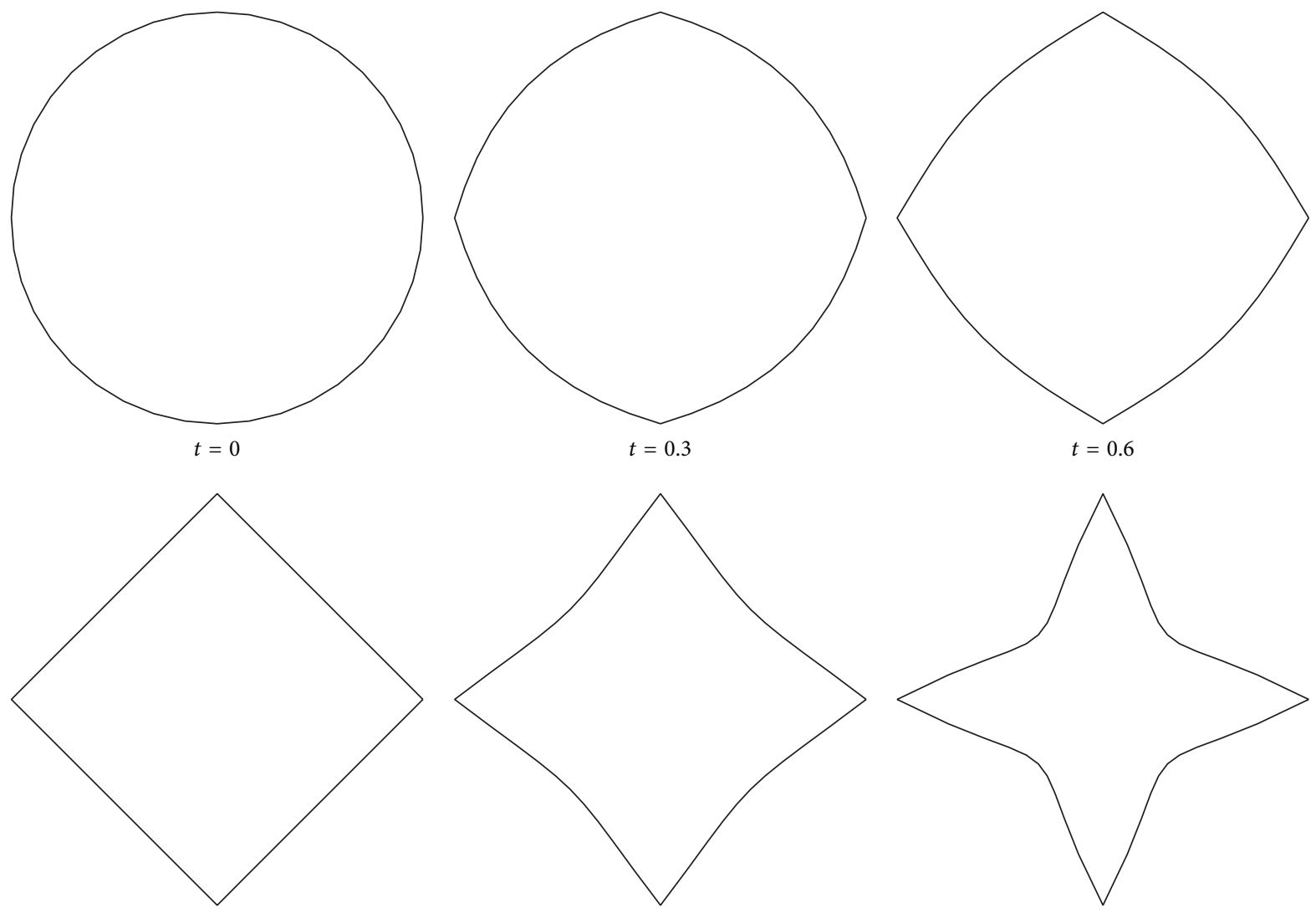

$t=1$

$t=1.3$

$t=1.6$

Figure 3: Blended shapes with different $t$ values.

all $C_{n}$ vertices is one shape blending result of $A$ and $B$, which could be formulated as the following expression:

$$
\begin{aligned}
C(t) & =(1-t) A+t B \\
& =\left[(1-t) A_{1}+t B_{1}, \ldots,(1-t) A_{n}+t B_{n}\right] \\
& =\left[C_{1}(t), \ldots, C_{n}(t)\right],
\end{aligned}
$$

where $n=12, A$ and $B$ present the source shape and the destination shape respectively, and the parameter $t$ is referred to as the blending coefficient. When $0 \leq t \leq 1$, it is interpolation, and when $t<0$ or $t>1$, it is extrapolation.

From (1), by varying the values of the blending coefficient $t$, it results in a collection of polygons as the blended results, as shown in Figure 3.

\section{Antenna Configuration}

The geometry and layout parameters of the proposed antenna are illustrated in Figure 4. The antenna is printed on a microwave substrate with the thickness $h=0.508 \mathrm{~mm}$, the dielectric constant $\varepsilon_{r}=3.66$, and the loss tangent equal to 0.004 . The antenna is located in $x-y$ plane with the normal direction along $z$-axis. The ground plane and the wide slot of the antenna are denoted as $L \times W$. and $L_{1} \times W_{1}$, respectively. The enclosing rectangle of the tuning stub is $l$ by $w$ and is

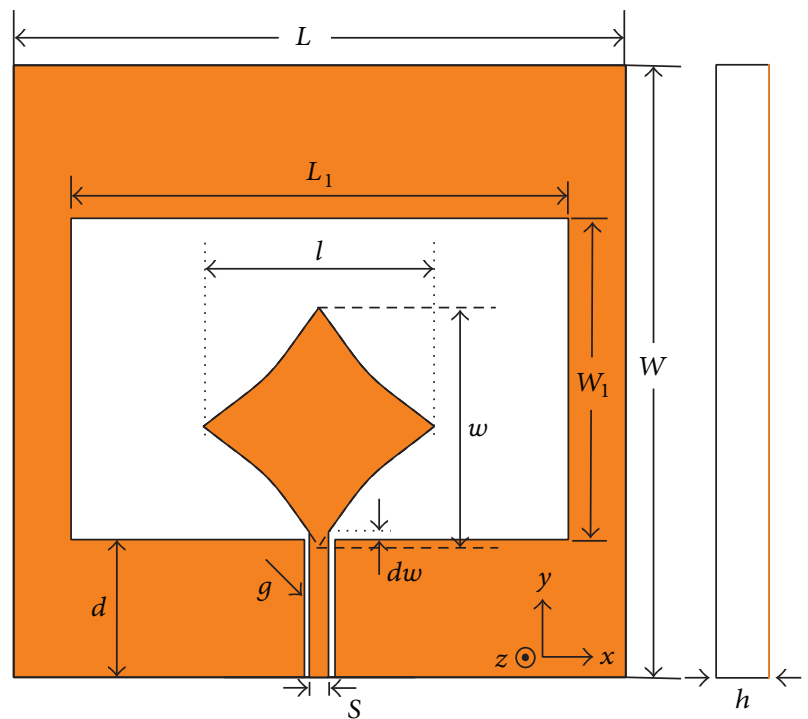

FIGURE 4: Geometry of the proposed antenna, with the blending coefficient $t=1.3$.

connected to a CPW feed line with its length of $d$ and width of $s$. The feed aperture is set to $g$. The feeding gap between the inner stub and the bottom edge of the wide slot is denoted as $d w$. 


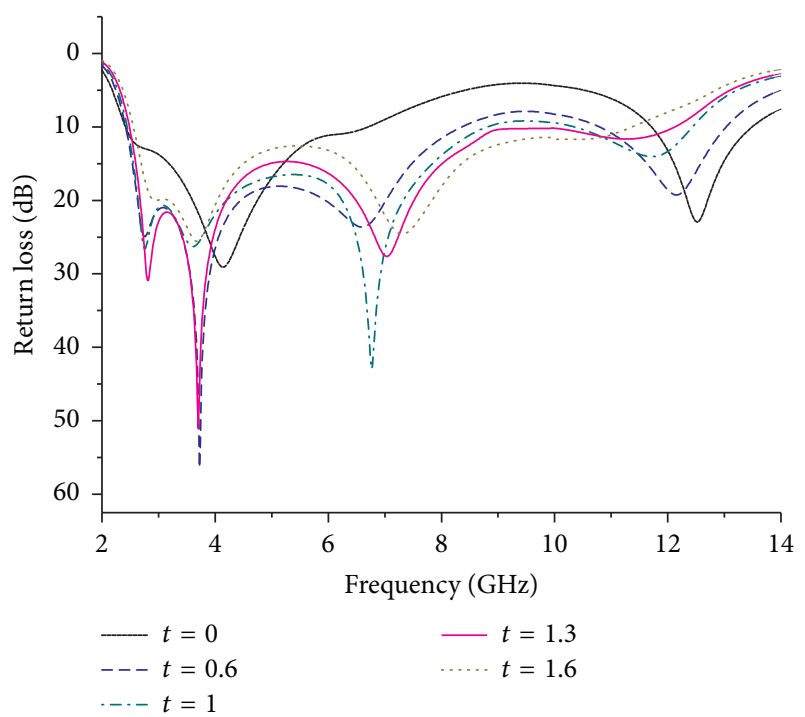

Figure 5: Return loss coefficients of different blending coefficient $t$ values.

TABLE 1: Bandwidth comparison for various $t$ values.

\begin{tabular}{lcccc}
\hline$t$ value & $\begin{array}{c}\text { Frequency } \\
\text { range }(\mathrm{GHz})\end{array}$ & $\begin{array}{c}\text { Absolute } \\
\text { bandwidth } \\
(\mathrm{GHz})\end{array}$ & $f_{c}(\mathrm{GHz})$ & $\begin{array}{c}\text { Fractional } \\
\text { bandwidth }\end{array}$ \\
\hline 0 & $2.42-6.7$ & 4.28 & 4.56 & $93.86 \%$ \\
0.3 & $2.37-7.79$ & 5.42 & 5.08 & $106.7 \%$ \\
0.6 & $2.42-8.36$ & 5.94 & 5.39 & $110.20 \%$ \\
1 & $2.45-8.8$ & 6.35 & 5.625 & $112.89 \%$ \\
1.3 & $2.48-12.12$ & 9.64 & 7.3 & $132.05 \%$ \\
1.6 & $2.56-11.37$ & 8.81 & 6.965 & $126.49 \%$ \\
1.9 & $2.57-10.62$ & 8.05 & 6.595 & $122.06 \%$ \\
\hline
\end{tabular}

The proposed antenna is simulated and optimized using Ansoft HFSS. The final dimensions of the fabricated prototype are as follows: $L=32 \mathrm{~mm}, W=32 \mathrm{~mm}, L_{1}=26 \mathrm{~mm}, W_{1}=$ $16.8 \mathrm{~mm}, d=7.2 \mathrm{~mm}, g=0.2 \mathrm{~mm}, s=1.0 \mathrm{~mm}, d w=0.13 \mathrm{~mm}$, $l=12 \mathrm{~mm}$, and $w=12 \mathrm{~mm}$.

Various shapes of the tuning stub can be constructed with different $t$ values, which finally affect the antenna impedance bandwidth. To further analyze the effect of the parameter, the return loss coefficient of the antenna is simulated for different $t$ values, as illustrated in Figure 5. It could be seen that neither the pie $(t=0)$ nor the diamond $(t=1.0)$ alone could cover the whole UWB band. However, when blending the two shapes, the impedance bandwidth improves gradually and when $t$ is equal to 1.3 , it has the largest impedance bandwidth extending from $2.48 \mathrm{GHz}$ to $12.12 \mathrm{GHz}$, indicating a $132 \%$ relative bandwidth.

Table 1 presents the simulated results when $t$ changes from 0 to 1.9 .

The bandwidth results in the above table could be plotted in a line chart for better illustration of the relationship between the antenna impedance bandwidth and the parameter $t$, as shown in Figure 6.

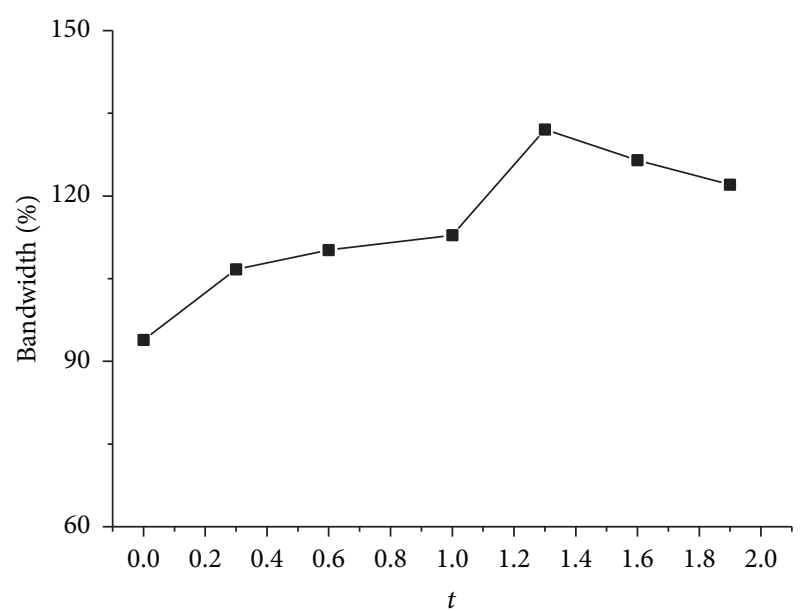

FIGURE 6: Simulated bandwidths of various $t$ values.

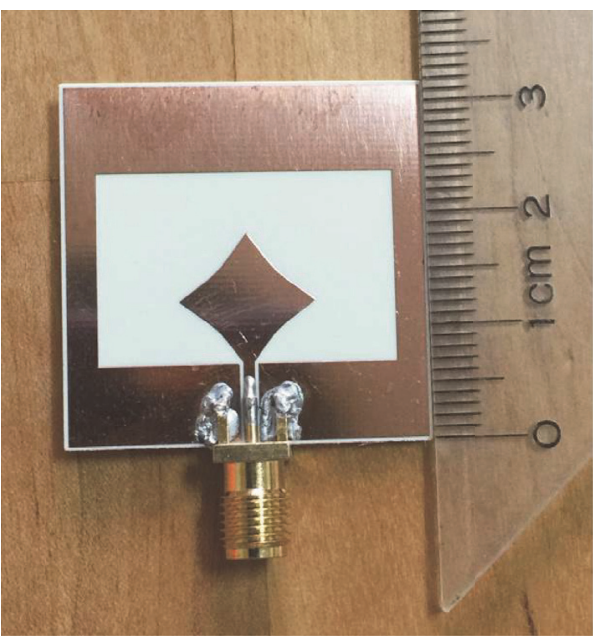

FIGURE 7: The fabricated antenna prototype.

For the fabricated prototype, the blending coefficient $t$ is selected to be $t=1.3$ when the antenna bandwidth reaches its maximum. Figure 7 shows the fabricated antenna prototype.

\section{Simulation and Experimental Results}

The antenna VSWR is measured by the Rohde \& Schwarz ZVM Network Analyzer $(10 \mathrm{MHz}-20 \mathrm{GHz})$. The antenna is fed through a SMA connector. The simulated and measured results of the VSWR are presented in Figure 8. It illustrates that the antenna impedance bandwidth extends from $3.05 \mathrm{GHz}$ to $11.7 \mathrm{GHz}$, indicating a $117 \%$ relative bandwidth. It is in excess of the UWB spectrum defined by FCC and also covers the frequency band of WLAN and WiMAX. It could be observed that there is a good agreement between the simulated and the measured results. With regard to the discrepancy between the simulated and the measured results, the simulation itself has its intrinsic errors. On the other hand, the SMA connector's side effects, the fabrication imperfections, the welding procedure, and the quality of 


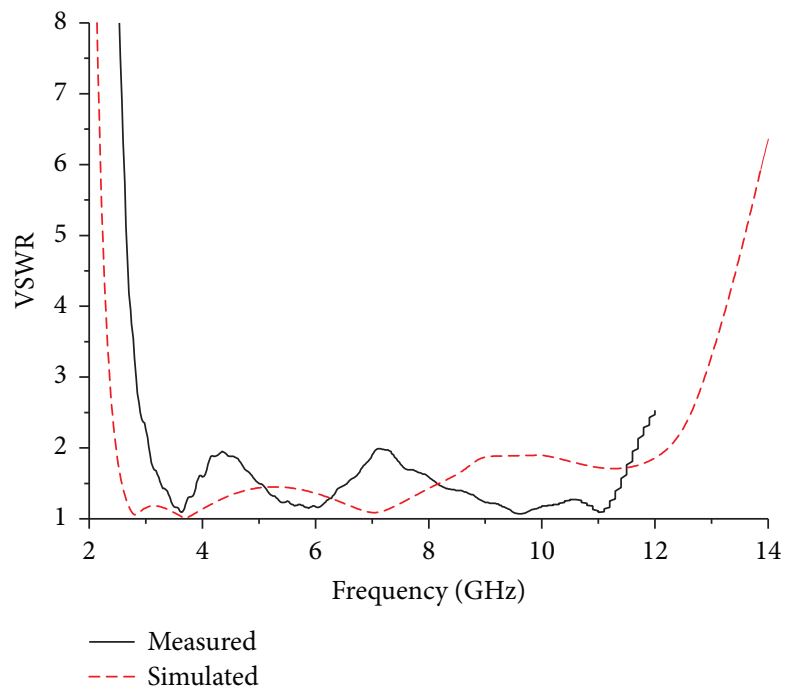

FIGURE 8: Simulated and measured VSWR.

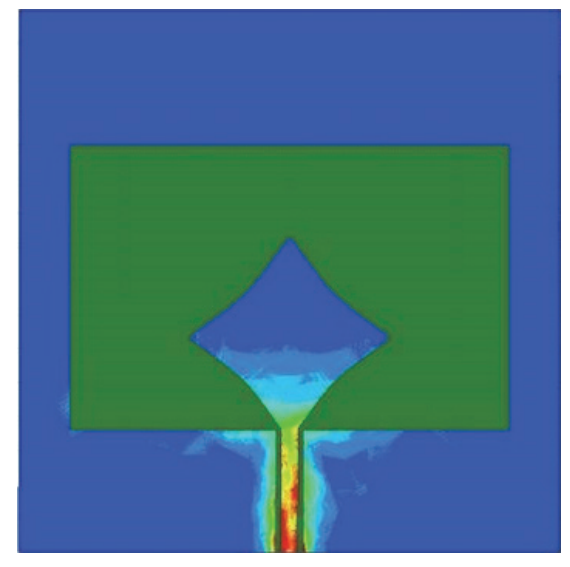

(a)

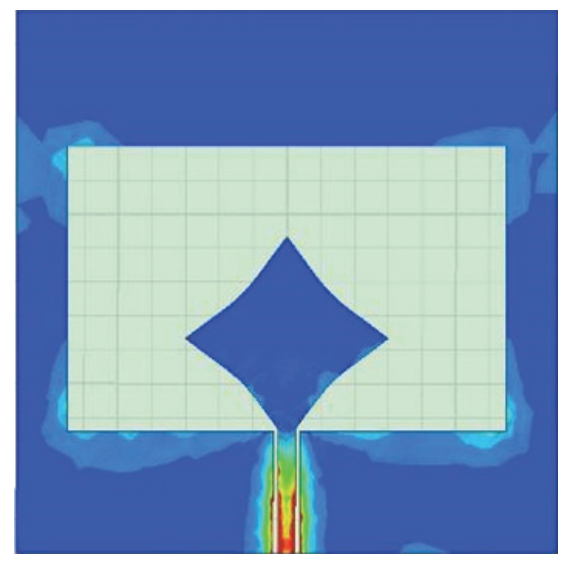

(c)
Jsurf (A_per_m)

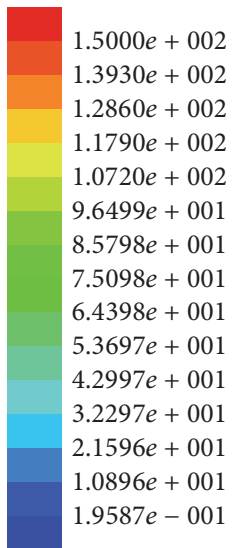

Jsurf (A_per_m)

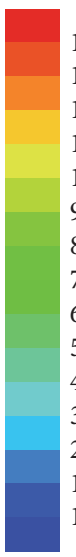

$1.5000 e+002$

$1.3930 e+002$

$1.2860 e+002$

$1.1790 e+002$

$1.0720 e+002$

$9.6499 e+001$

$8.5798 e+001$

$7.5098 e+001$

$6.4398 e+001$

$5.3697 e+001$

$4.2997 e+001$

$3.2297 e+001$

$2.1596 e+001$

$1.0896 e+001$

$1.9587 e-001$

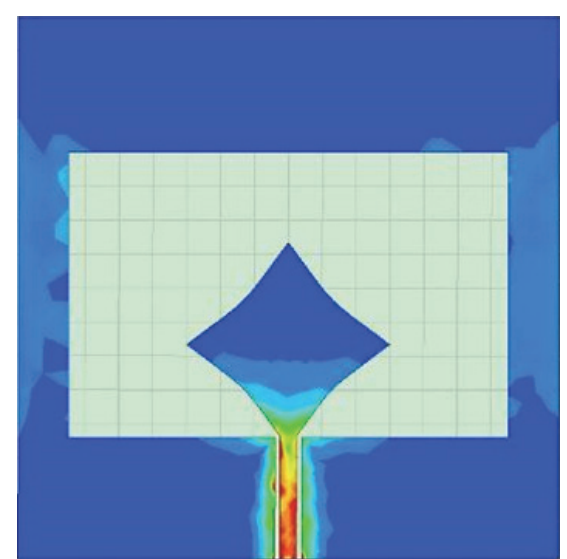

(b)

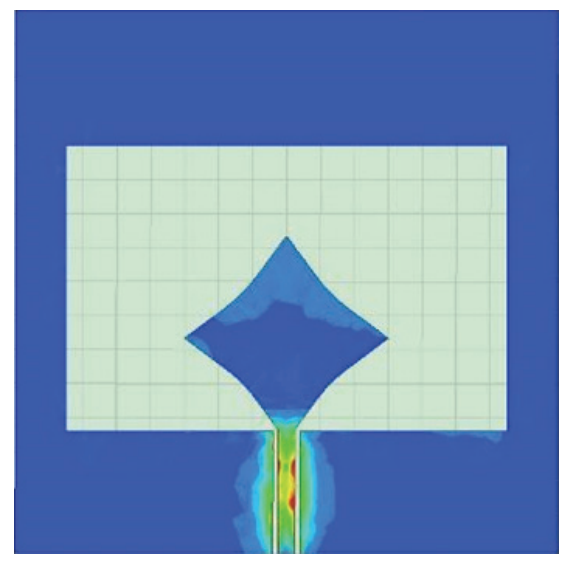

(d)
Jsurf (A_per_m)

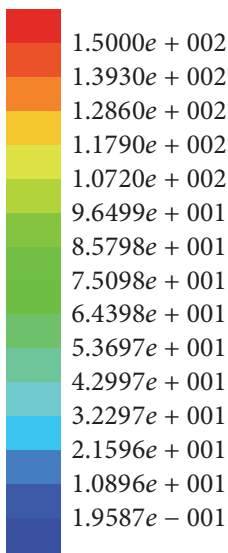

Jsurf (A_per_m)

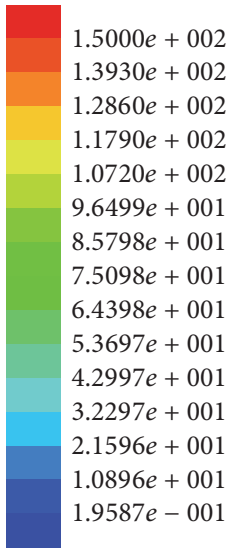

Figure 9: Simulated current distributions at (a) $2.8 \mathrm{GHz}$, (b) $3.6 \mathrm{GHz}$, (c) $7 \mathrm{GHz}$, and (d) $11.5 \mathrm{GHz}$. 

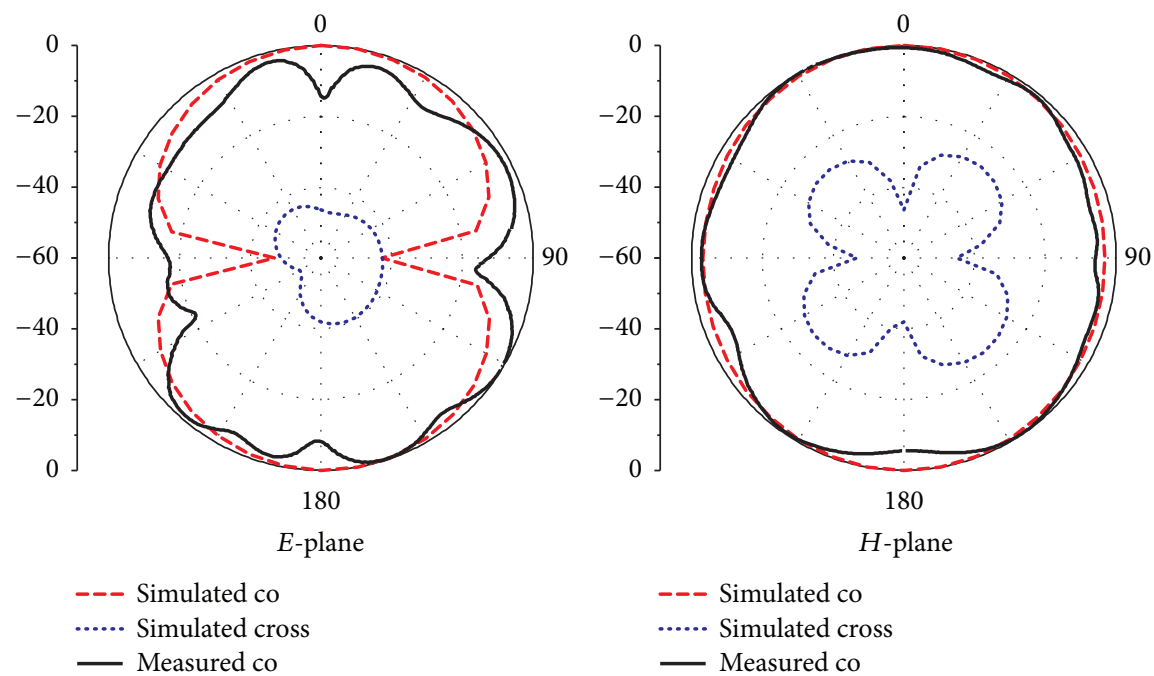

--- Simulated co

..... Simulated cross

— Measured co

- Measured co

(a)
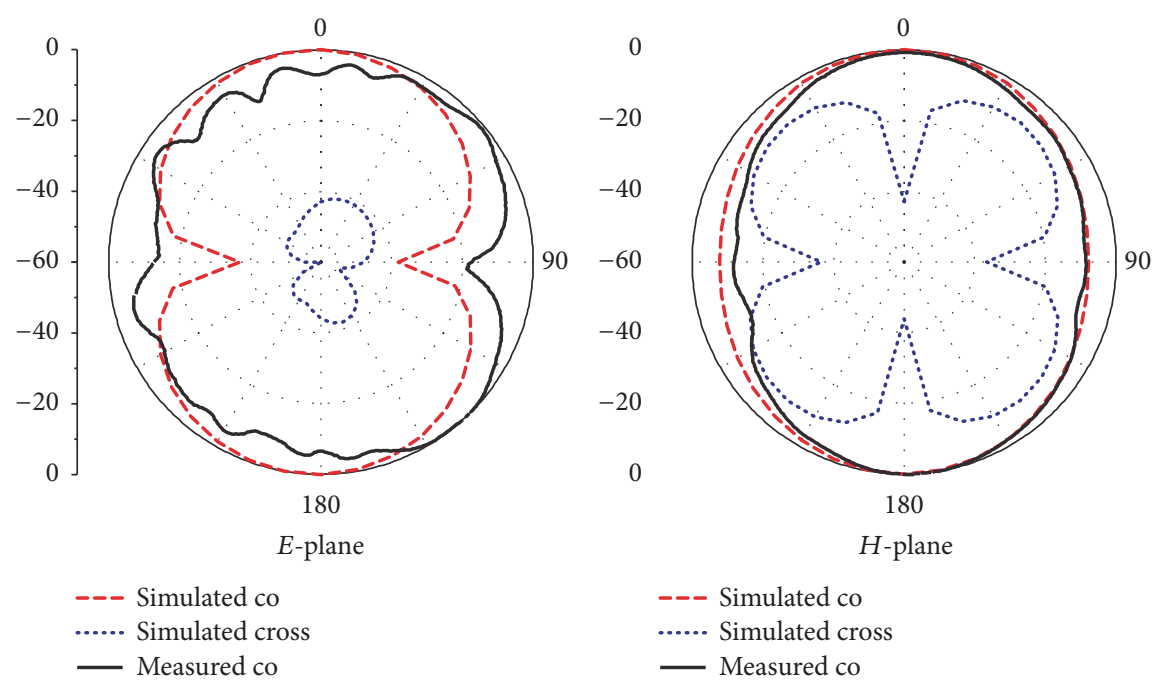

$$
\begin{aligned}
& \text {--- Simulated co } \\
& \text {..... Simulated cross } \\
& \text { — Measured co }
\end{aligned}
$$

(b)
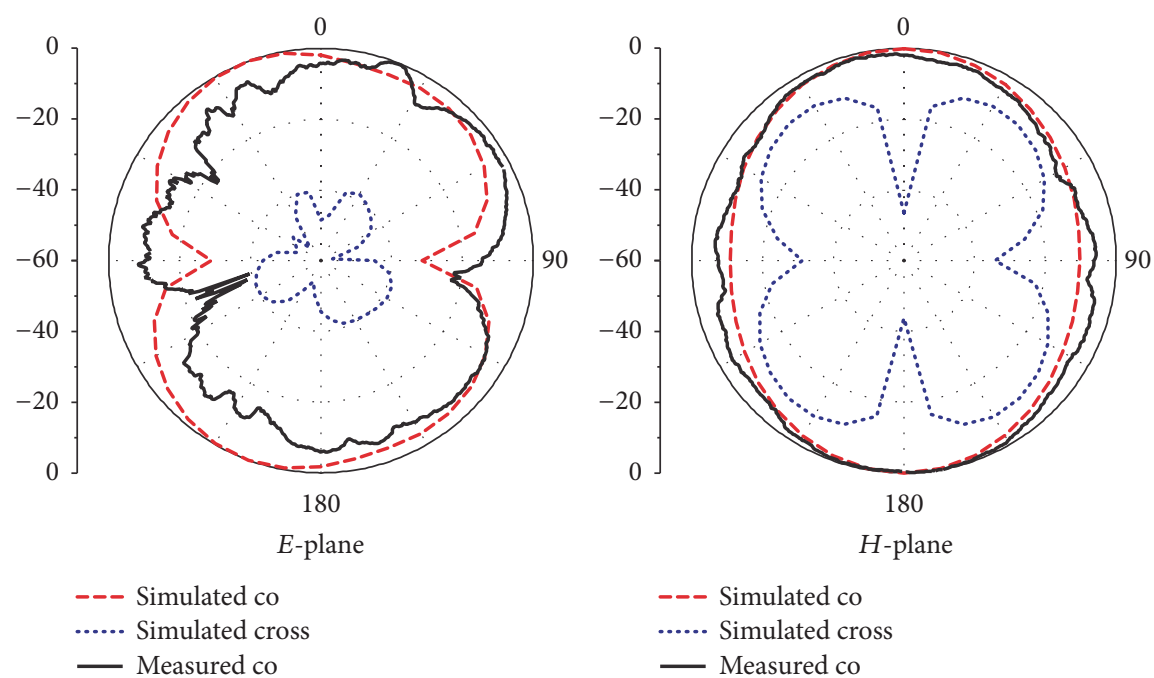

(c)

FIGURE 10: Simulated and measured radiation pattern at (a) $3 \mathrm{GHz}$, (b) $6 \mathrm{GHz}$, and (c) $9 \mathrm{GHz}$. 
the used microwave substrate material will all potentially contribute to the discrepancy.

To better understand the UWB characteristic of the antenna [23], the simulated current distributions at different frequencies are presented in Figure 9. Figure 9(a) shows the current pattern near the first resonance at $2.8 \mathrm{GHz}$. The current pattern near the second resonance at $3.6 \mathrm{~Hz}$ is given in Figure 9(b), indicating approximately a secondorder harmonic. Figure 9(c) illustrates two more complicated current patterns at $7 \mathrm{GHz}$ and $11.5 \mathrm{GHz}$, corresponding to the third-order and fourth-order harmonics, respectively. These current distributions indicate that the UWB characteristic of the antenna is attributed to the overlapping of a sequence of appropriate spaced resonance modes.

The radiation patterns of the proposed antenna are displayed in $x$ - $y$ plane (or $E$-plane) and $y$ - $z$ plane (or $H$ plane), respectively. Figure 10 illustrates the simulated and the measured normalized radiation patterns of the antenna at $3 \mathrm{GHz}, 6 \mathrm{GHz}$, and $9 \mathrm{GHz}$. It can be clearly seen that the simulated and measured results have a good agreement with each other. In E-plane, the radiation patterns are almost bidirectional at lower frequencies, while there are quite some distortions at higher frequencies. In $H$-plane, all radiation patterns conserve a relatively stable omnidirectional characteristic over all the three frequencies.

\section{Conclusion}

A novel design method of printed CPW-fed slot antenna using the shape blend algorithm has been proposed and investigated for wideband applications. The impact of the blending coefficient $t$ on the antenna impedance bandwidth is analyzed in detail. To verify the proposed design and the simulation results, the prototype is designed, fabricated, and measured. There is a good agreement between the simulated results and measured ones. It shows that the measured impedance bandwidth extends from $3.05 \mathrm{GHz}$ to $11.7 \mathrm{GHz}$, indicating a $117 \%$ relative bandwidth. The shape blending algorithm has been proven to be a novel effective and convenient method in the wideband antenna design process.

\section{Conflicts of Interest}

The authors declare that there are no conflicts of interest regarding the publication of this paper.

\section{Acknowledgments}

This work was supported by the National Natural Science foundation of China (Grant 61501153).

\section{References}

[1] R. L. Lovestead, Helical Antenna Optimization Using Genetic Algorithms [Ph.D. dissertation], Virginia Polytechnic Institute and State University, Blacksburg, Va, USA, 1999.

[2] L. A. Griffiths, C. Furse, and Y. C. Chung, "Broadband and multiband antenna design using the genetic algorithm to create amorphous shapes using ellipses," IEEE Transactions on Antennas and Propagation, vol. 54, no. 10, pp. 2776-2782, 2006.

[3] J. W. Jayasinghe, J. Anguera, and D. N. Uduwawala, "A simple design of multi band microstrip patch antennas robust to fabrication tolerances for GSM, UMTS, LTE, and Bluetooth applications by using genetic algorithm optimization," Progress In Electromagnetics Research M, vol. 27, pp. 255-269, 2012.

[4] N. Jin and Y. Rahmat-Samii, "Parallel particle swarm optimization and wide-band patch antenna designs," IEEE Transactions on Antennas and Propagation, vol. 53, no. 11, pp. 3459-3468, 2005.

[5] J. R. Pérez and J. Basterrechea, "Comparison of different heuristic optimization methods for near-field antenna measurements," IEEE Transactions on Antennas and Propagation, vol. 55, no. 3, pp. 549-555, 2007.

[6] S. Karimkashi and A. A. Kishk, "Invasive weed optimization and its features in electromagnetics," IEEE Transactions on Antennas and Propagation, vol. 58, no. 4, pp. 1269-1278, 2010.

[7] O. Sigmund, "On the usefulness of non-gradient approaches in topology optimization," Structural and Multidisciplinary Optimization, vol. 43, no. 5, pp. 589-596, 2011.

[8] H.-D. Chen, "Broadband CPW-fed square slot antennas with a widened tuning stub," IEEE Transactions on Antennas and Propagation, vol. 51, no. 8, pp. 1982-1986, 2003.

[9] T. A. Denidni and M. A. Habib, "Broadband printed CPW-fed circular slot antenna," Electronics Letters, vol. 42, no. 3, pp. 135 136, 2006.

[10] J. Liang, C. C. Chiau, X. Chen, and C. G. Parini, "Study of a printed circular disc monopole antenna for UWB systems," IEEE Transactions on Antennas and Propagation, vol. 53, no. 11, pp. 3500-3504, 2005.

[11] X.-L. Liang, S.-S. Zhong, and W. Wang, "Tapered CPW-FED printed monopole antenna," Microwave and Optical Technology Letters, vol. 48, no. 7, pp. 1242-1244, 2006.

[12] X.-F. Bai, S.-S. Zhong, and X.-L. Liang, "Leaf-shaped monopole antenna with extremely wide bandwidth," Microwave and Optical Technology Letters, vol. 48, no. 7, pp. 1247-1250, 2006.

[13] M. K. Khattak and S. Kahng, "Design of a UHF wide-band antenna with a compact notch filter," IET Microwaves, Antennas \& Propagation, vol. 10, no. 15, pp. 1625-1632, 2016.

[14] C. Wei and S. Frank, "High performance SOI RF switch for healthcare application," International Journal of Enhanced Research in Science, Technology \& Engineering, vol. 5, no. 10, pp. 23-28, 2016.

[15] W. Cai, J. Xu, and S. Wang, "Low power SI class E power amplifier for healthcare application," International Journal of Electronics Communication and Computer Engineering, vol. 7, no. 6, article 290, 2016.

[16] W. Cai, J. Xu, and L. Huang, "Low power SI class E power amplifier and Rf switch for health care," Informatics Engineering, vol. 4, no. 4, pp. 7-14, 2016.

[17] W. Cai, C. Li, and S. W. Luan, "SOI RF switch for wireless sensor network," Advances in Engineering: An International Journal, vol. 1, no. 2, pp. 1-9, 2016.

[18] M. John and M. J. Ammann, "Wideband printed monopole design using a genetic algorithm," IEEE Antennas and Wireless Propagation Letters, vol. 6, pp. 447-449, 2007.

[19] L. Lizzi, F. Viani, R. Azaro, and A. Massa, "Optimization of a spline-shaped UWB antenna by PSO," IEEE Antennas and Wireless Propagation Letters, vol. 6, pp. 182-185, 2007. 
[20] A. Wu, B. Guan, and Z. Zhang, "A wideband printed slot antenna using shape blending," in Proceedings of the 2016 11th International Symposium on Antennas, Propagation and EM Theory (ISAPE '16), pp. 92-94, Guilin, China, October 2016.

[21] S. E. Chen and R. E. Parent, "Shape averaging and its applications to industrial design," IEEE Computer Graphics and Applications, vol. 9, no. 1, pp. 47-54, 1989.

[22] M. Akimaliev and M. F. Demirci, "Improving skeletal shape abstraction using multiple optimal solutions," Pattern Recognition, vol. 48, no. 11, pp. 3504-3515, 2015.

[23] L. Gong, K. Y. Chan, and R. Ramer, "Phase correction of the electric field for a dielectric loaded substrate integrated waveguide $H$-plane horn antenna," Microwave and Optical Technology Letters, vol. 59, no. 3, pp. 584-588, 2017. 


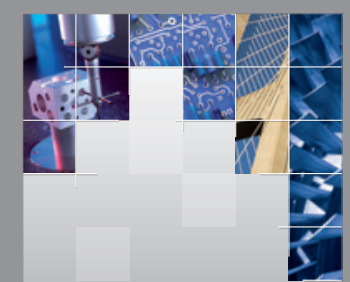

\section{Enfincering}
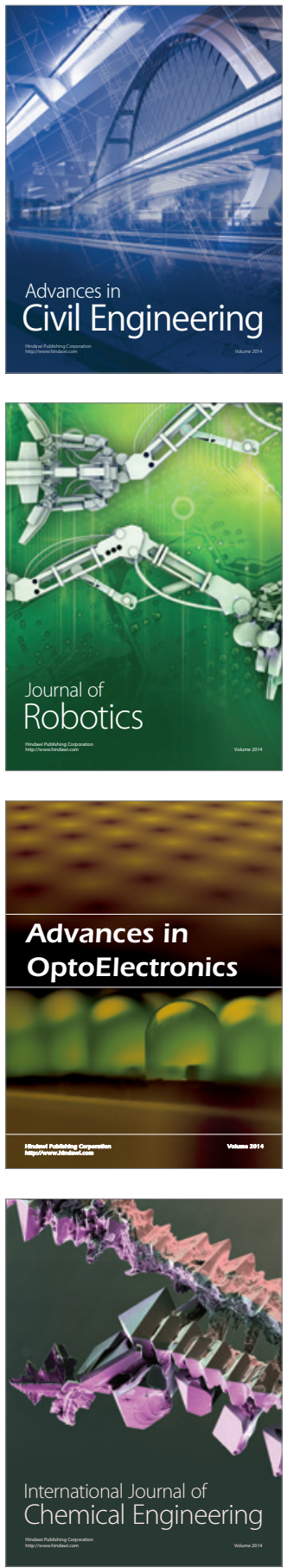

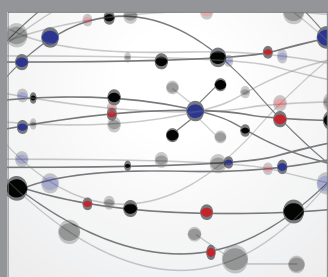

The Scientific World Journal

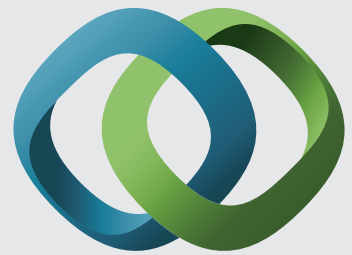

\section{Hindawi}

Submit your manuscripts at

https://www.hindawi.com
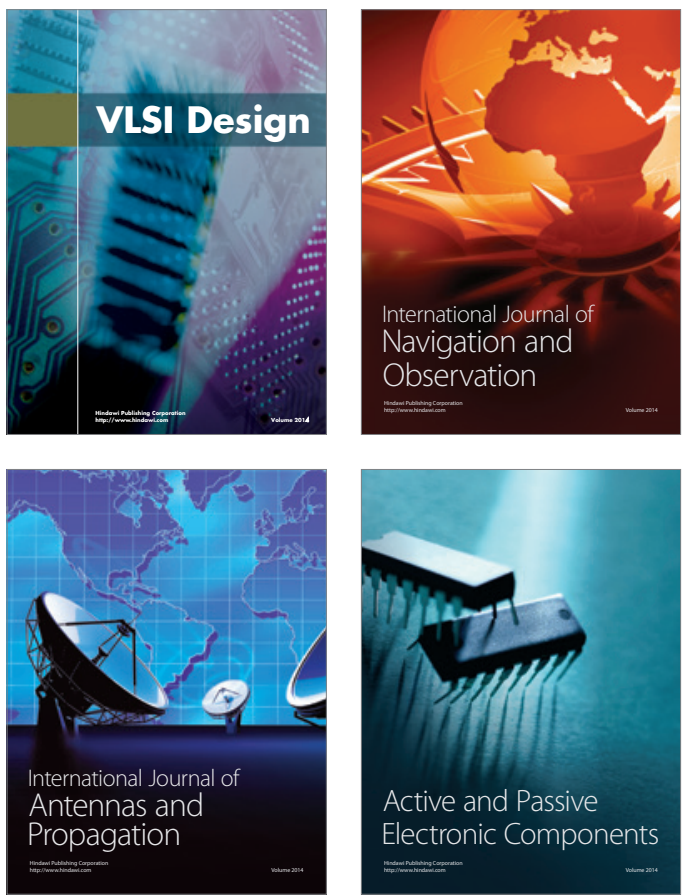
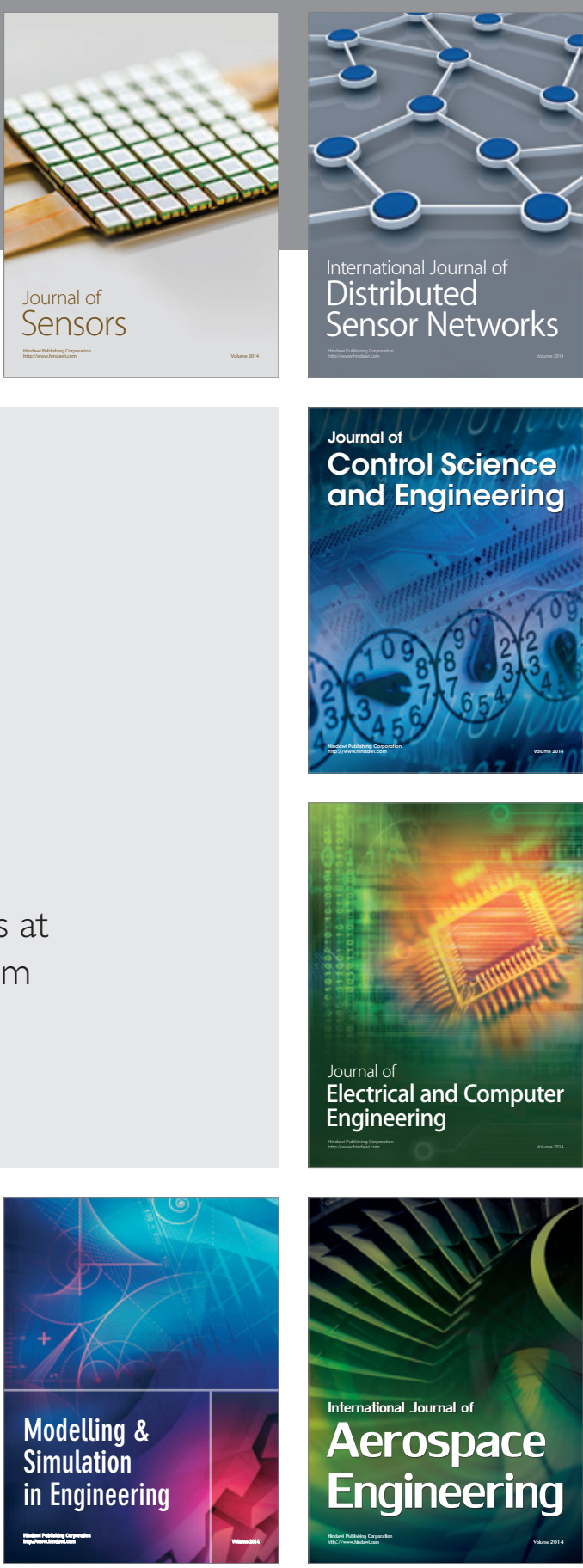

International Journal of

Distributed

Sensor Networks

$-$

Joumal of

Control Science

and Engineering
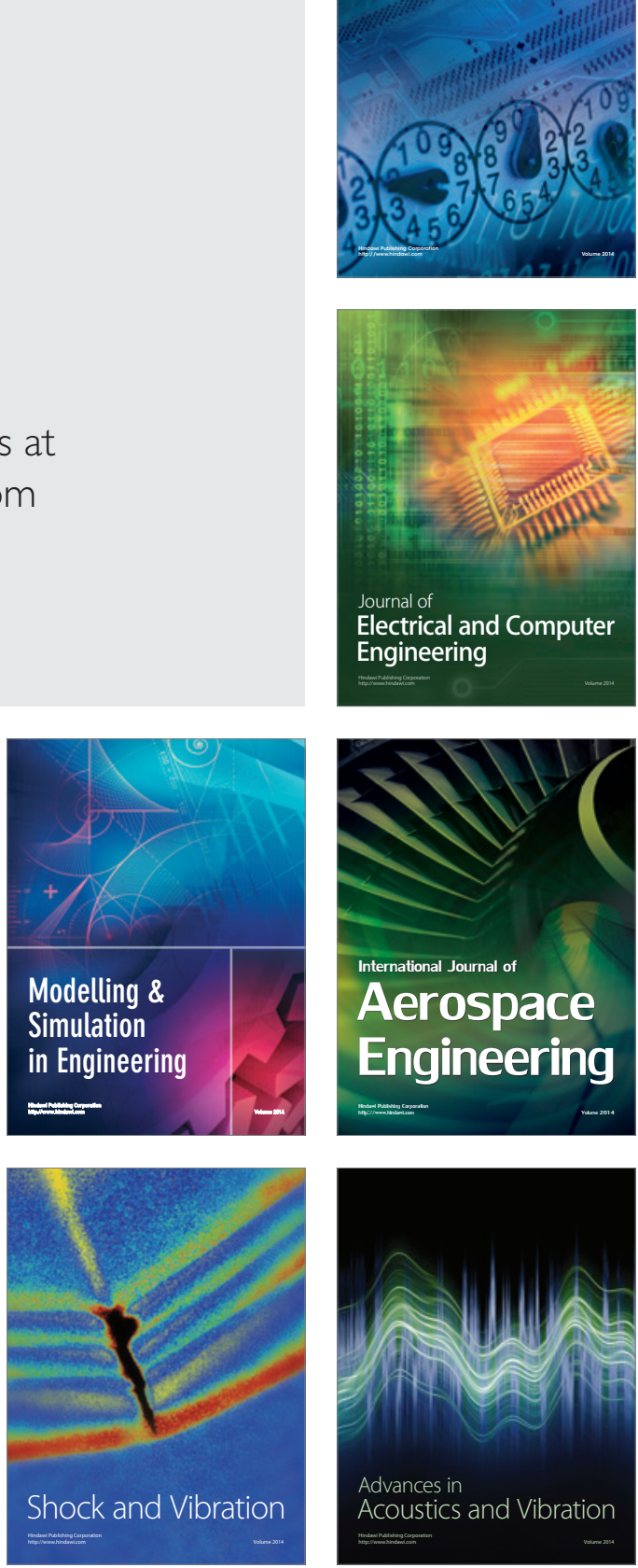